\title{
ESTIMATIVA DE PERDAS DE SOLOS EM UMA BACIA HIDROGRÁFICA SOB O CULTIVO DE FRUTÍFERAS, NO MUNICÍPIO DE VALINHOS (SP)
}

\author{
Antonio Carlos Vitte* \\ Luís Ribeiro Vilela Filho**
}

\section{RESUMO:}

Este artigo tem por objetivo estimar as perdas de solo em uma bacia hidrográfica sob o cultivo de frutíferas utilizando a Equação Universal de Perdas de Solo, a partir da metodologia proposta por Vitte (1997), que pressupõe o uso de indicadores morfométricos e cartográficos para o cálculo de cada índice constitutivo da USLE. Sabe-se que a erosão dos solos é um processo natural de esculturação da crosta terrestre, mas que ultimamente vem sendo intensificada com os tipos e práticas de uso das terras. Nesse sentido, o avanço dos estudos relativos à erosão dos solos torna-se cada vez mais importante para a preservação das terras agricultáveis e o uso das equações empíricas é um valioso instrumento para estes estudos.

\section{PALAVRAS-CHAVE:}

Equação Universal de Perdas de Solo, bacia hidrográfica, erosão, agricultura.

\section{ABSTRACT:}

This article has for goal esteem the soil losses in a basin drainage under the cultivation of fruitful using the Soil Losses Universal Equation, from the proposed methodology for Vitte (1997), that presupposes the mophometric indicators use and cartographic for the calculation of each USLE's constituent index. It is known that the soils erosion is a natural process of sculturation of the terrestrial crust, but that has lately been intensified with the kinds and earths use practices. In this sense, the advance of the relative studies to the soils erosion become more and more important for the preservation of the farmable earths and the use of the empiric equations is a valuable instrument for these studies.

\section{KEY WORDS:}

Soil Losses universal equation, basin drainage, erosion, agriculture.

\section{O Processo erosivo}

Segundo CUNHA (1997), a erosão dos solos é um processo normal no desenvolvimento da paisagem, sendo responsável pela remoção do material de superfície por meio do vento, gelo ou água. Sob estas condições, a erosão é considerada um processo natural. Por outro lado, a erosão acelerada dos solos ocorre em intensidade superior à erosão normal sendo atribuída, usualmente, ao resultado das atividades humanas sob determinadas condições de clima, vegetação, solos e relevo.

A erosão, enquanto processo, é resultante da dinâmica de um determinado sistema ambiental que está em desequilíbrio provocado por interferências naturais ou antrópicas em um de seus fatores. Esse desequilíbrio é resultado do balanço ecodinâmico de um determinado sistema ambiental (TRICART, 1977). 
De acordo com BERTONI e LOMBARDI NETO (1990), a chuva é um dos fatores de maior importância para a erosão, sendo que a intensidade, a duração e a freqüência são as propriedades mais importantes que afetam o processo erosivo. Considerando-se que a duração da chuva é o complemento da intensidade, a combinação de ambas determinará a chuva total. Da mesa forma, a freqüência das chuvas influenciará nas perdas de solo, mesmo com chuvas de menor intensidade. Caso os intervalos sejam curtos, o solo terá um alto teor de umidade, o que favorece o escoamento superficial.

Quanto ao relevo, a maior influência está no comprimento e na declividade das vertentes (as mais íngremes facilitam a erosão dos solos na medida em que aumentam o escoamento superficial), enquanto a cobertura vegetal, em função da densidade, pode oferecer maior ou menor proteção ao solo, interferindo na intensidade da erosão.

Por outro lado, atualmente os problemas relacionados à degradação ambiental têm sido alvo da mobilização de dirigentes do setor público e de grupos representativos da sociedade civil, e, sem dúvida, dentre as questões ambientais, a erosão dos solos está entre as que tem causado maior preocupação (VITTE, 1997). Com isso, reforça-se a necessidade da compreensão dos processos responsáveis pela erosão a fim de que se possa ter um entendimento sobre como e porque ela ocorre, e, dessa forma, poder associar o desenvolvimento com a conservação do solo.

\section{Caracterização da área de estudo}

A área de estudo compreende a bacia hidrográfica do córrego "Espírito Santo", afluente da margem direita do médio curso do Ribeirão dos Pinheiros e está localizada entre as coordenadas 7463.000 e 298.000 UTM e, 7460.000 e 301.000 UTM, no município de Valinhos (SP), situado à $7 \mathrm{~km}$ de Campinas (SP) e à $90 \mathrm{~km}$ de São Paulo, capital, e que faz fronteira com Campinas, Indaiatuba, Itatiba, Morungaba e Vinhedo (figura 1).

Valinhos faz parte da Região Metropolitana de Campinas (RMC), sendo que no ano 2000 a sua população era de 82.973 habitantes, sendo 78.506 correspondentes à população urbana e o restante, 4.467, à população rural, o que representa um índice de urbanização de $94,6 \%$.

Figura 1: Localização de Valinhos e municípios adjacentes, no Estado de São Paulo

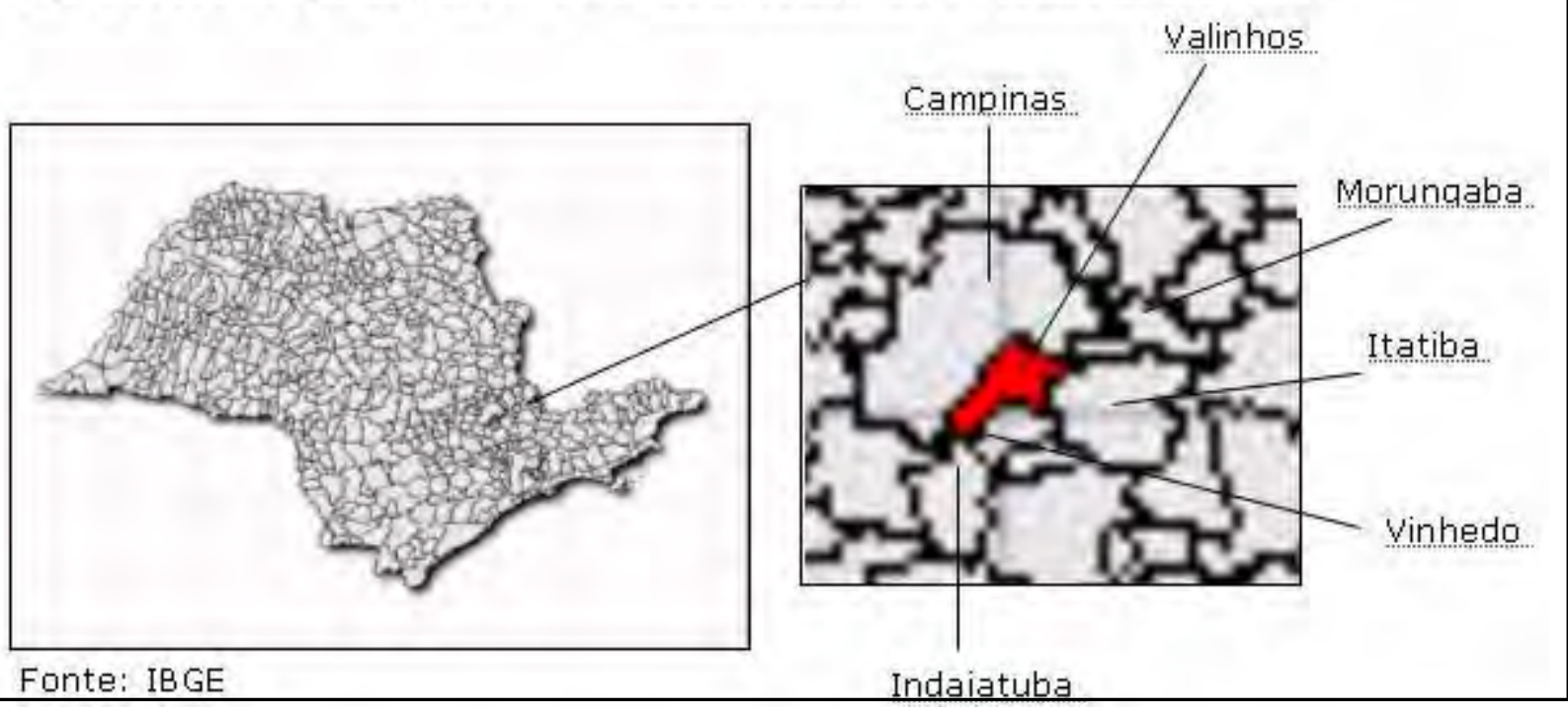


Estimativa de perdas de solos em uma bacia hidrográfica sob

\section{Geologia}

Segundo o Mapa Geológico do Estado de São Paulo (IPT, 1981), em Valinhos a litologia predominante é do Complexo Amparo (Proterozóico inferior), incluindo gnaisses a biotita, hornblenda e granada com grau variável de migmatização, associados a migmatitos de estruturas diversas, com intercalações não individualizadas de quartzitos, xistos, anfibolitos, gonditos e mataultrabasitos, além de incluir migmatitos bandados de paleossomas granulíticos e anfibolíticos, granulitos diversos migmatizados, migmatitos homogêneos, anatexitos, com pequenos resisters de biotita, gnaisses e quartzitos.

O Maciço de Morungaba, entre Valinhos, Morungaba e Pedreira, configura-se como um bloco tectônicamente soerguido em meio a metamorfitos migmatizados dos complexos Itapira e Amparo. Trata-se de uma culminação granítica tardia da evolução petrológica das rochas Varginha e Socorro, em seus termos metamórfico-migmatíticos (IPT, 1981).

\section{Geomorfologia}

Segundo o IPT (1981), o município de Valinhos está situado na zona de transição entre o Planalto Atlântico, sub-zona do Planalto de Jundiaí, e a Depressão Periférica, sub-zona do Médio Tietê. O relevo de Valinhos caracterizase por apresentar morros e morrotes com predominância de declividades médias a altas, acima de 15\%, com altitudes variando de 600 a 650 metros, próximos aos principais cursos d'água, e 850 a 950 metros nos topos mais elevados, como a Serra dos Cocais.

Quanto aos solos, segundo o relatório e - mapa do Levantamento de Reconhecimentos de Solos do Estado de São Paulo (1960), em Valinhos ocorrem o Podzólico vermelho amarelo, o Podzólico Vermelho Amarelo Orto (PV), que ocupa $45 \%$ da área total do município e localizase no Planalto Atlântico, os solos Podzolizados com cascalho, que ocupam $40 \%$ da área total do município, e ocorre no Planalto Atlântico o Latossolo Vermelho Amarelo, Latossolo
Vermelho Amarelo Orto (LV) e finalmente o Litosol.

\section{Clima}

No município de Valinhos predominam os tipos climáticos $\mathrm{Cfa}$ e $\mathrm{Cfb}$, e os dados pluviométricos para Valinhos foram obtidos da estação meteorológica D3-002 Salto Grande

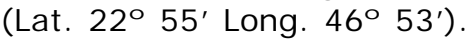

Por meio destes dados constatou-se que no município de Valinhos a precipitação média anual registrada no período foi de $1504,2 \mathrm{~mm}$. A estação chuvosa estende-se de outubro a março, onde ocorrem cerca de $72 \%$ da precipitação média anual, enquanto que o período de maior estiagem é entre os meses de julho e agosto, representando apenas 5\% da precipitação média anual.

\section{Estimativa de perdas de solo}

Os primeiros trabalhos sobre avaliação das perdas de solo utilizando equações foram desenvolvidos por cientistas norte-americanos na década de 40, na região do Corn Belt dos Estados Unidos.

De acordo com VITTE (1997), os experimentos desenvolvidos no meio-oeste americano durante o período de 1940-54 culminaram em equações que relacionavam as perdas de solo com os efeitos da declividade e do comprimento da rampa, de práticas conservacionistas e de fatores de uso e manejo do solo. Em 1946, um comitê americano revisou individualmente os fatores e dados existentes e, após incluírem o fator de erosividade da chuva, produziram a equação de Musgrave, que foi amplamente utilizada nas estimativas de erosão em bacias hidrográficas incluídas em programas para controle de inundações.

No Brasil, os primeiros trabalhos sobre a Equação Universal de Perdas de Solo foram desenvolvidos por BERTONI et al. (1975), utilizando dados existentes para as condições do Estado de São Paulo. Desde então, diversos 
trabalhos vêm sendo desenvolvidos por várias instituições do país, dentre elas o Instituto Agronômico de Campinas - IAC, visando avaliar os fatores da equação não só para São Paulo, como também para outras regiões.

Nesse sentido, VITTE (1997) destaca a importância destes trabalhos em função da Equação Universal de Perdas de Solo, que, apesar de ser um valioso instrumento para predição, tem, porém, sua adoção limitada pelas dificuldades existentes na determinação dos parâmetros que a compõem, pois estes baseiam-se em resultados de parcelas experimentais que necessitam de um longo período mensuraçao para atingir índices de predição estatísticamente confiáveis, demandando, assim, grandes finaciamentos para sua realização

Segundo BERTONI \& LOMBARDI NETO (1990), a falta de métodos para adaptar os valores dos fatores determinados às propriedades das chuvas, às práticas agrícolas locais, à duração do período de desenvolvimento da cultura, além de outras variáveis, impossibilitou a difusão das equações a novas áreas. Este problema foi solucionado em 1954 no Runoff and Soil-Loss Data Center, do Agricultural Research Service, onde foi desenvolvida a atual equação de perdas de solo através de análises que determinaram a inclusão de melhorias na equação, tais como: um índice de erosão da chuva; um método de avaliar os efeitos do manejo de uma cultura em função das condições climáticas locais; um fator quantitativo de erodibilidade do solo; um método que considere os efeitos de interpelações de certas variáveis, como nível de produtividade, seqüência de culturas e manejo dos resíduos. Estas alterações propiciaram a aplicação generalizada da equação, de modo que o modelo passou a denominar-se Equação Universal de Perdas de Solo (USLE). Posteriormente, WICHMEIER \& SMITH (1978) revisaram-na, atualizando e incorporandoIhe novos dados disponíveis, resultando na seguinte versão:

$$
\mathrm{A}=\mathrm{RKLSCP} \text {, onde: }
$$

$\mathrm{A}=$ perda média anual de solo ( $\mathrm{T} / \mathrm{ha}) ; \mathrm{R}=$ fator erosividade da chuva ( $\mathrm{Mj} / \mathrm{ha} . \mathrm{mm} / \mathrm{ha}) ; \mathrm{K}=$ fator erodibilidade do solo ( $\mathrm{Mj} / \mathrm{ha} . \mathrm{mm} / \mathrm{ha}) ; \mathrm{L} \mathrm{S}=$ fator topográfico englobando a declividade e o comprimento das vertentes; $\mathrm{C}=$ fator uso/manejo dos solos; $\mathrm{P}=$ fator práticas conservacionistas.

Segundo BERTONI \& LOMBARDI NETO (1990), estas alterações possibilitaram a superação das restrições climáticas e geográficas contidas nos primeiros estudos, propiciando a aplicação generalizada da equação.

\section{Comprimento e Grau do Declive (Fator LS)}

A ação exercida pelas águas pluviais é condicionada por duas variáveis do relevo que constituem o fator topográfico: a declividade e o comprimento das vertentes.

De acordo com BERTONI \& LOMBARDI NETO (1990), o fator LS representa a relação entre as perdas de solo para um grau de declive e um comprimento de rampa qualquer e as perdas em uma parcela unitária com 25 metros de comprimento e $9 \%$ de declive. Estas medidas de comparação resultaram de pesquisas que permitiram representar matematicamente a relação existente entre as perdas de solo e o grau do declive (fator $\mathrm{S}$ ) e as perdas de solo e o comprimento do declive (fator $\mathrm{L}$ ). A resolução da equação para estimar as perdas de solo, no entanto, é facilitada quando se combinam os elementos L e S.

Neste trabalho, o levantamento do comprimento das rampas foi realizado a partir do mapeamento, com base em carta topográfica na escala 1:10.000, da rede de drenagem e dos divisores de águas da bacia, seguido da secção do córrego "Espírito Santo" em sub-bacias. Em seguida, baseado na escala da carta topográfica, estabeleceu-se as classes de distâncias entre os interflúvios e os talvegues que foram aplicadas seguindo-se a inclinação do terreno.

Dessa forma, para cada sub-bacia foram determinadas uma ou mais classes de comprimento de rampa. Estes seguimentos foram denominados de "parcelas" e passaram a se constituir nas unidades básicas para o estabelecimento dos outros parâmetros da equação. 
Em toda a bacia foram delimitadas 160 parcelas, das quais sobressaem-se as de comprimento de vertente até 100 metros e de
100 a 200 metros, com $42 \%$ e $32 \%$, respectivamente (figura 2 ).

Figura 2: Mapa de Comprimento das vertentes

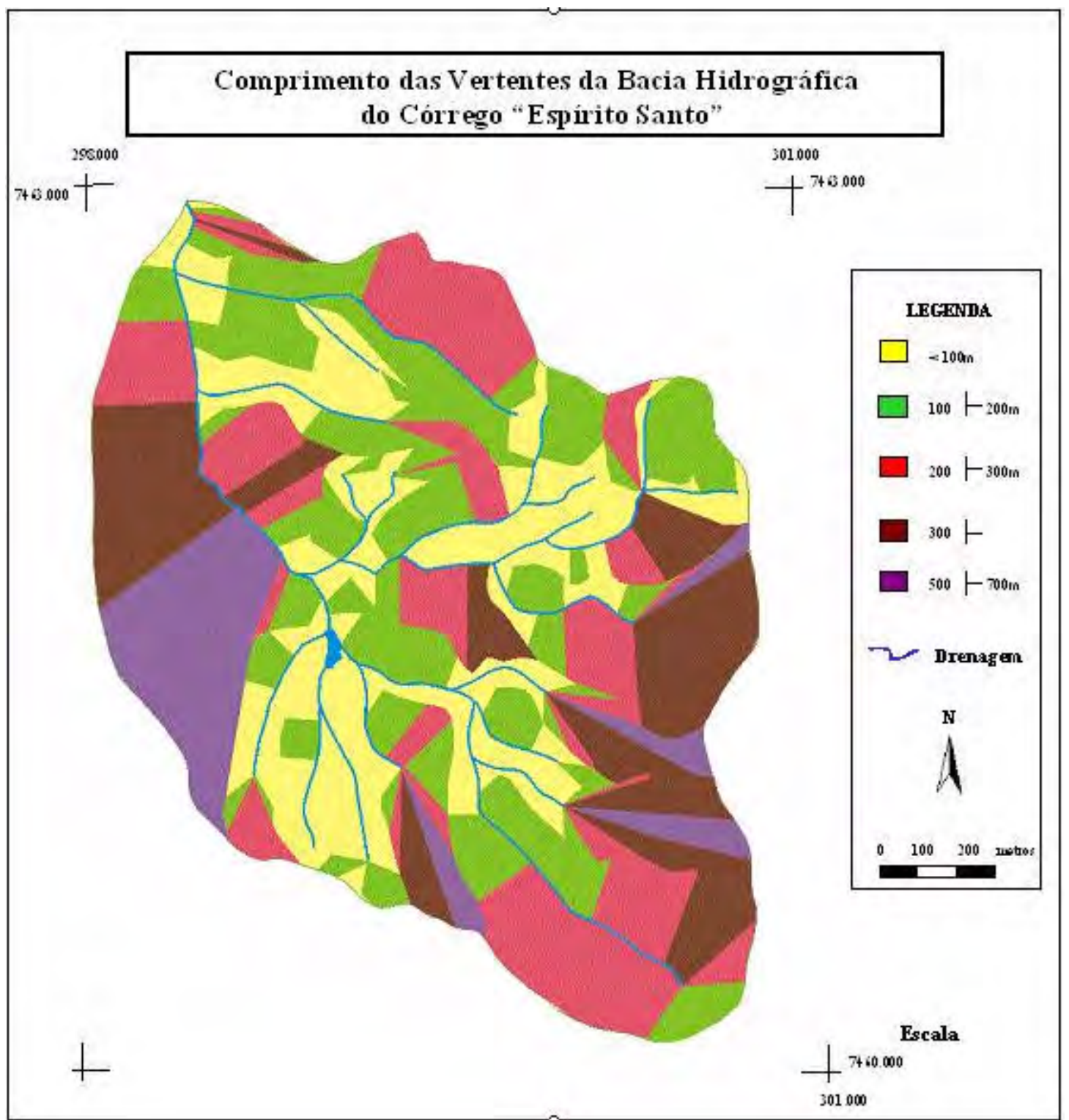

Fonte: Trabalho de gabinete 
Com relação à declividade, utilizou-se o software ArcView GIS 3.2 para a geração do mapa clinográfico composto por seis intervalos de classes (figura 3). Posteriormente, a declividade de cada uma das parcelas foi obtida através da superposição do mapa básico, que continha suas delimitações, ao mapa clinográfico. Em seguida, multiplicou-se o valor intermediário de cada classe pela sua área correspondente em porcentagem. Ao final, dividiuse a somatória dos totais pela somatória das áreas de cada classe, estabelecendo-se, assim, o valor individual da declividade de cada parcela. A tabela 1 apresenta este cálculo para uma das parcelas.

Figura 3: Mapa de declividade

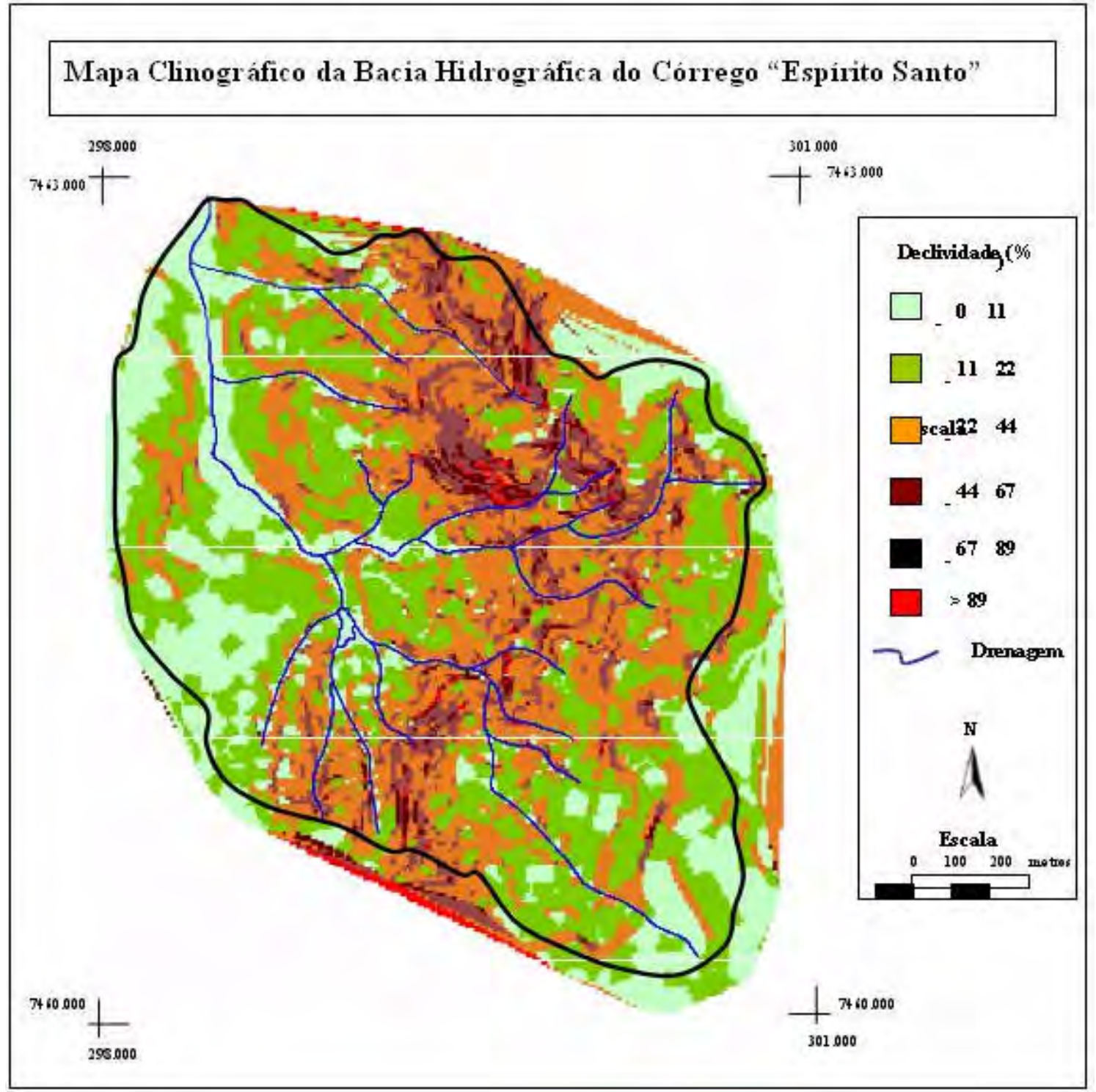

Fonte: Trabalho de gabinete 
Tabela 1: Cálculo da declividade para uma das 160 parcelas da bacia hidrográfica do córrego "Espírito Santo".

\begin{tabular}{|c|c|c|c|}
\hline \multicolumn{5}{|c|}{ Parcela 13 } \\
\hline Classes & $\begin{array}{c}\text { Média das } \\
\text { Classes }\end{array}$ & Área (\%) & Total \\
\hline $0-5$ & 2.5 & 5.1 & 12.75 \\
\hline $5-10$ & 7.5 & 46.4 & 348 \\
\hline $10-20$ & 15 & 38.2 & 573 \\
\hline $20-30$ & 25 & 10.3 & 257.5 \\
\hline $30-40$ & 35 & 0 & 0 \\
\hline $40-60$ & 50 & 0 & 0 \\
\hline & \multicolumn{4}{|c|}{ Declividade $=11.9$} \\
\hline
\end{tabular}

Fonte: Trabalho de gabinete

Estabelecidos os valores de declividade e comprimento de vertente, VITTE (1997) propõe para o cálculo do fator topográfico o modelo de WISCHMEIER e SMITH (1965), transcrito por BERTONI, LOMBARDI NETO e BENATTI JR (1975), adaptado para unidades métricas:

$$
\text { LS }=\text { L 0,5/100 }(1,36+0,97 \mathrm{~S}+
$$
$\left.0,13855 S^{2}\right)$

Onde: $\mathrm{L}=$ comprimento da rampa em metros $^{1} ; \mathrm{S}=$ declividade, em porcentagem.

Com os dados utilizados para a obtenção de LS, estruturou-se uma planilha no software Excel 7.0, obtendo-se, em seguida seus respectivos valores. $O$ fragmento desta planilha é apresentado no quadro 2. Em seguida, baseado nos valores obtidos para LS, foram estabelecidos cinco intervalos de classes (quadro 1), que foram aplicados aos dados para a geração do mapa do fator LS na bacia (figura 4).

Quadro 1: Intervalos de classes e suas respectivas quantidades e poroentagens

\begin{tabular}{|c|c|c|c|c|c|}
\hline & \multicolumn{5}{|c|}{ Intervalos de classes } \\
& $<35$ & $35-70$ & $70-105$ & $\begin{array}{c}105 \\
140\end{array}$ & $>140$ \\
\hline No Absoluto & 118 & 28 & 7 & 5 & 2 \\
\hline$(\%)$ & 73.8 & 17.5 & 4.4 & 3.1 & 1.3 \\
\hline
\end{tabular}

Fonte: Trabalho de gabinete

Quadro 2: Fragmento da planilha de cálculo do fator LS para as parcelas da bacia hidrográfica do córrego "Espírito Santo"

\begin{tabular}{|c|c|c|c|}
\hline Parcela & Comp. Vertente (m) & Declividade (\%) & LS \\
\hline 1 & 50 & 2.5 & 1.2 \\
\hline 2 & 150 & 4.4 & 6.2 \\
\hline 3 & 250 & 4.3 & 10.1 \\
\hline 4 & 400 & 7.2 & 31.0 \\
\hline 5 & 600 & 5.2 & 30.4 \\
\hline 6 & 250 & 10.7 & 34.5 \\
\hline 7 & 150 & 11.6 & 23.4 \\
\hline 8 & 50 & 7.0 & 3.7 \\
\hline 2 & 50 & 8.6 & 5.0 \\
\hline 10 & 150 & 8.3 & 14.2 \\
\hline 11 & 50 & 10.6 & 6.8 \\
\hline
\end{tabular}




\begin{tabular}{|c|c|c|c|}
\hline 12 & 50 & 7.2 & 3.9 \\
\hline 13 & 150 & 11.9 & 24.4 \\
\hline 14 & 250 & 11.3 & 37.5 \\
\hline 15 & 400 & 10.2 & 6.4 \\
\hline 16 & 250 & 8.9 & 26.2 \\
\hline 17 & 150 & 5.3 & 7.8 \\
\hline 18 & 50 & 2.5 & 1.2 \\
\hline 19 & 50 & 5 & 2.4 \\
\hline 20 & 150 & 9.6 & 17.6 \\
\hline 21 & 50 & 5.4 & 2.6 \\
\hline 22 & 50 & 3.9 & 1.8 \\
\hline 23 & 150 & 9.2 & 16.5 \\
\hline 24 & 250 & 10.1 & 31.5 \\
\hline 25 & 400 & 7.4 & 32.4 \\
\hline 26 & 250 & 8.9 & 26.1 \\
\hline 27 & 150 & 10.4 & 19.7 \\
\hline 28 & 50 & 6.5 & 3.3 \\
\hline 29 & 50 & 10.2 & 6.4 \\
\hline 30 & 150 & 7.2 & 11.6 \\
\hline 31 & 50 & 8.4 & 4.8 \\
\hline 32 & 150 & 5.5 & 8.2 \\
\hline 33 & 250 & 8.4 & 24.1 \\
\hline 34 & 50 & 14.9 & 7.2 \\
\hline 35 & 50 & 11.0 & 7.2 \\
\hline
\end{tabular}

\section{Quadro 2 cont.}

Fonte: Trabalho de gabinete
A distribuição do fator LS na bacia apresentou predominância dos valores abaixo de 35 , correspondendo a $73,8 \%$ do total. Estas áreas também são caracterizadas por apresentarem os menores valores de declividade. Por outro lado, as áreas dotadas de maior declividade resultaram em valores mais elevados para LS.

\section{Erosividade das chuvas (Fator $\mathbf{R}$ )}

Segundo BERTONI \& LOMBARDI NETO (1990), estudos realizados demonstram que o melhor índice para expressar a erosividade de uma chuva é o produto da energia cinética total pela sua intensidade. Esse fator foi denominado El.

LOMBARDI NETO \& MOLDENHAUER (1980) encontraram alta correlação para a regressão linear entre o índice médio de erosão mensal e um coeficiente de chuva (modificado do coeficiente de chuva de Fournier). A relação obtida foi:

$$
E I=67,355\left(r^{2} / p\right)^{0,85}
$$

em que:

EI = índice médio de erosão mensal; $r=$ preciptação média mensal em milímetros; $p=$ preciptação média anual em milímetros

A soma dos valores dos índices médios de erosão mensal corresponde ao índice médio de erosão anual, ou seja, ao fator $\mathrm{R}$.

LOMBARDI NETO et al. (1980), utilizando esta equação, estabeleceram os valores de El para cento e quinze locais previamente selecionados do Estado de São Paulo. No mesmo trabalho, os dados de chuva foram analisados para diferentes locais quanto ao potencial de erosão durante o ano. As porcentagens mensais do total anual do El para um 
local foram comparadas com dados similares dos adjacentes, estabelecendo-se os valores médios das porcentagens. Em seguida foram separadas quatorze áreas relativamente homogêneas onde a distribuição do potencial de erosão anual era uniforme (BERTONI \& LOMBARDI NETO 1990).

Estas informações facilitam a aplicação da equação de perdas de solo, viabilizando sua utilização em qualquer área do estado de São Paulo.

Para a determinação da erosividade das chuvas na bacia hidrográfica do córrego "Espírito
Santo", foram utilizados dados de precipitação, obtidos por meio do Banco de Dados Pluviométricos do Estado de São Paulo, da estação meteorológica D3-002 - Salto Grande (Lat. 22은 55' Long. 46 53'), referentes ao período de 1974 a 1994 (Tabela 1). Em seguida aplicou-se a equação El $=67,355\left(r^{2}\right)$ p) 0,85 , proposta por LOMBARDI NETO \& MOLDENHAUER, obtendo-se o valor de R.

A tabela 2 mostra os Els encontrados para o período analisado, a partir dos quais obteve-se o valor de 6.055 para $R$.

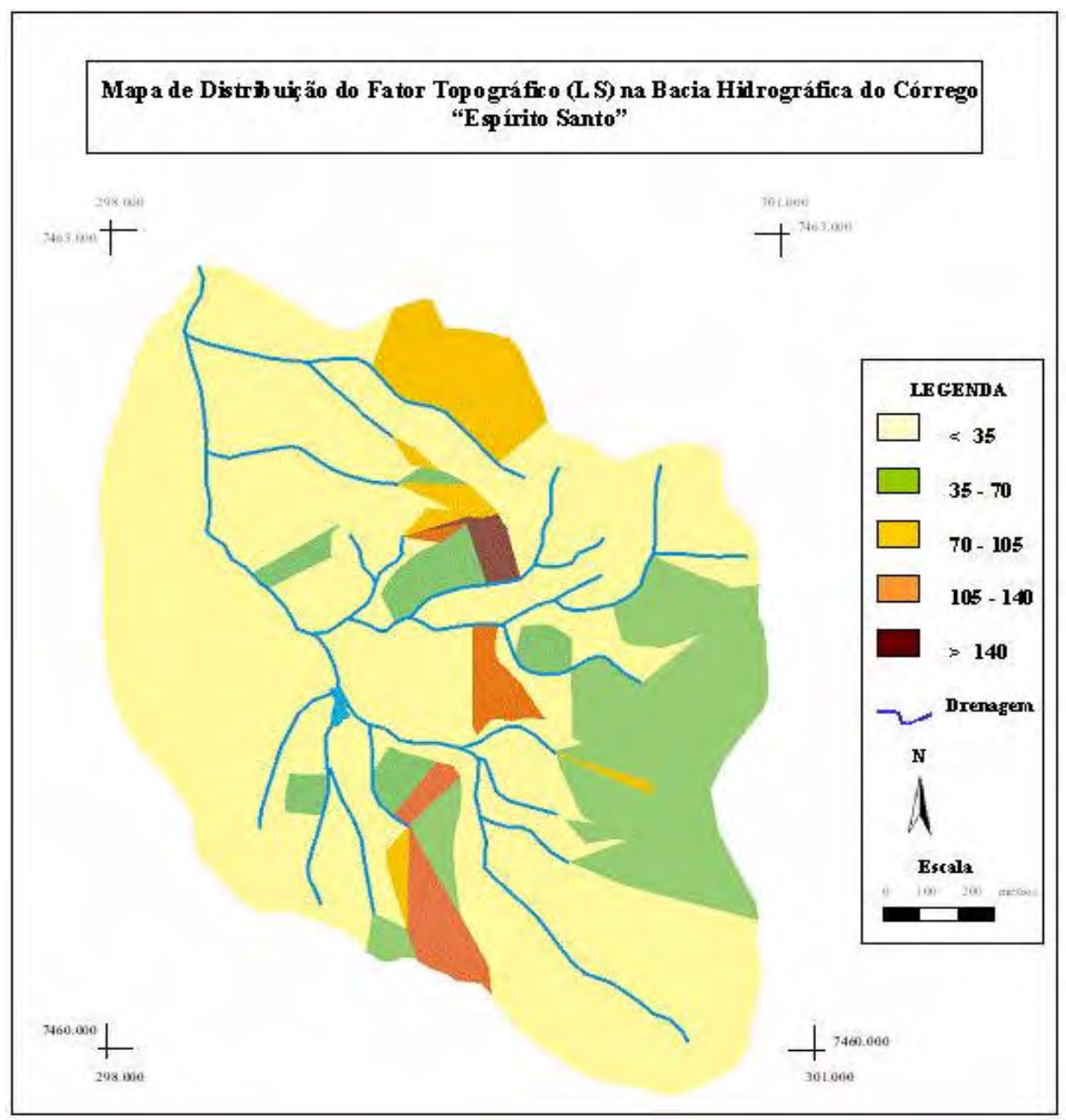

Figura 4: Mapa do fator LS

Fonte: Trabalho de gabinete 
Tabela 2: Médias mensais dos índices de erosão $(\mathrm{EI})$ obtidos através de $\mathrm{EI}=67,355(\mathrm{r} 2 / \mathrm{P}) 0,85$

\begin{tabular}{|c|c|c|c|c|c|c|c|c|c|c|c|c|c|}
\hline & \multicolumn{12}{|c|}{ EI MENSAL } & EI MEDIO \\
\hline ANO & JAN & FEV & MAR & ABR & MAA] & JUN & JUL & $A G 0$ & SET & 0UT & NOV & $\mathrm{DEZ}$ & ANUAL \\
\hline 1974 & 25.180 .5 & 1670.7 & $3.417,1$ & 2.2080 & 34,4 & 4.223 .8 & 0,0 & 75.1 & 880,4 & $7.82,1$ & $13.742,4$ & $13.742,4$ & 6083,1 \\
\hline 1975 & $8.521,1$ & 13.765 .4 & 2.697 .3 & 310 & 206,1 & 18,5 & 489,4 & 0,0 & 335,3 & 12.621 .6 & 189743 & $18.974,3$ & $6.415,4$ \\
\hline 1976 & $6.540,2$ & 13.451 .1 & 7.695 .5 & 2.192 .4 & $4.178,1$ & $1.816,3$ & 4830,8 & $.126,3$ & 82545 & 8.745 .6 & 5.6832 & $5.683,2$ & 6016,4 \\
\hline 1977 & $18.683,0$ & 1.7015 & $3,782,0$ & 5.7183 & 52,0 & 621.9 & 92,8 & 352.7 & 6.4443 & 6.538 .4 & 230588 & $23.058,8$ & 7515,4 \\
\hline 1978 & $3.609,0$ & 22888 & $5.396,4$ & 672 & $2,218,0$ & 1.359 .1 & 4270,0 & 5,9 & 7186 & 18.328 .2 & 7.7278 & 7.727 .8 & 4.476 .4 \\
\hline 1979 & $5.616,2$ & 4.7046 & $4.071,0$ & $2.602,4$ & $3.785,7$ & 8,5 & 1098,9 & 058,2 & 32733 & $5.502,0$ & 7519,4 & $7.519,4$ & 3980,0 \\
\hline 1980 & $13.093,3$ & $4.423,2$ & 1.009 .4 & $13.946,1$ & 162,5 & $2.487,4$ & 33,9 & 156,5 & 340,7 & $4.080,1$ & $15.440,3$ & $15.440,3$ & 6057,7 \\
\hline 1981 & $16.798,0$ & 26668 & $4.295,8$ & 587.7 & 0,8 & $1.001,8$ & 148,1 & 84,8 & 3308 & 12.624 .1 & $11.557,1$ & $11.557,1$ & 10,9 \\
\hline 1982 & 23.408 .9 & 49182 & $6.556,7$ & 6070 & 507,2 & $5.799,3$ & 542,6 & 150,1 & 29,4 & 4.248 .5 & 138800 & $13.880,0$ & 6294,4 \\
\hline 1983 & $17.490,3$ & 15.446 .6 & $8.095,2$ & 4.9872 & $10.044,4$ & 6.369 .2 & 488,9 & 37.8 & 9.7743 & 4.452 .2 & 9057,4 & 9.057 .4 & 940,1 \\
\hline 1984 & $13.916,8$ & 6573 & $1.681,2$ & 9.282 .8 & $3.722,6$ & 0.5 & 32,9 & $.088,4$ & 7.4599 & 5.398 .5 & $13.405,3$ & $13.405,3$ & 8254,3 \\
\hline 1985 & $9.842,6$ & 7028,4 & $11,582,0$ & 4.085 .4 & $2.458,5$ & 364,5 & 64,6 & 186,2 & 3.8486 & $2.796,7$ & 11872,5 & $11.872,5$ & $5.484,4$ \\
\hline 1986 & $5.044,9$ & 72812 & 11.219 .6 & 1.0763 & $5.697,0$ & 6.8 & 836,3 & $4.864,6$ & 4098 & 9. & 17836,1 & $17.836,1$ & 6810,2 \\
\hline 1987 & 20.278 .9 & 69808 & 10.191 .5 & 1.881 .4 & $12.579,9$ & $2.755,0$ & 65,2 & $6 \infty, 2$ & 22079 & 2.421 .6 & 6.4098 & $6.409,6$ & 6020.6 \\
\hline 1988 & $16.045,4$ & 52773 & $11.215,8$ & $2 . \$ 54,1$ & $4.859,9$ & 423.8 & 0,0 & 0,0 & 295 & $4.674,3$ & 13.6202 & $13.620,2$ & 6051,7 \\
\hline 1989 & $15.124,5$ & $10.187,1$ & 1.611 .4 & 1.7548 & 133,9 & 1.148 .6 & 7897.7 & 311,1 & 18666 & 15.799 .7 & 49278 & $4.927,8$ & 5.457 .4 \\
\hline 1990 & $24,383,0$ & 29612 & 11.727 .8 & $\$ 32,6$ & $1.102,8$ & 137.6 & 5.744 .3 & 602.7 & 2.575 .6 & $1.904,8$ & 8270,6 & $8.270,6$ & 5.717 .8 \\
\hline 1991 & 26.266 .1 & 88512 & $25.251,3$ & $7.486,1$ & 473,1 & 430,9 & 213,0 & 18,0 & 1250,4 & 3.708 .7 & 11938.3 & $11,938,3$ & $8.152,1$ \\
\hline 1992 & $9.417,6$ & 19970 & 7.287 .5 & $\$ 020$ & $2.350,1$ & 39,3 & 601,7 & 229,9 & 3817,7 & $13.448,9$ & 7.1232 & $7.123,2$ & 4528,2 \\
\hline 1993 & 13.431 .4 & 14867.7 & $3.286,5$ & 2.5339 & $4.553,5$ & 789,0 & 0,7 & 760,8 & 9001,1 & 4.069 .3 & 75965 & $7.596,5$ & 5.705 .6 \\
\hline 1994 & $14.833,2$ & $7.716,1$ & 0,0 & 5,3 & $1.044,8$ & 714,4 & 839,1 & 0,0 & $D D$ & $4.288,6$ & 26337,4 & 26.337 .4 & 6991,4 \\
\hline & & & & & & & & & & & & & \\
\hline & & & & & & & & & & & & $\pi$ & 55 \\
\hline
\end{tabular}

Fonte: Pesquisa de gabinete

\section{Erodibilidade do solo (Fator K)}

É uma característica individual de cada solo que mede a sua susceptibilidade em sofrer erosão. $O$ fator $K$ corresponde à perda de solo por unidade do fator $\mathrm{R}$.

O valor quantitativo do fator $K$ é determinado experimentalmente em parcelas unitárias com 25 metros de comprimento e $9 \%$ de declive, preparadas como se fossem receber uma cultura de milho, com práticas de manejo para evitar o aparecimento de ervas daninhas ou formação de crostas ( BERTONI \& LOMBARDI NETO, 1990).
A obtenção experimental do fator $K$ é muito demorada e custosa. LOMBARDI NETO \& BERTONI (1975) estudaram uma série de perfis para dois agrupamentos de solo do estado de São Paulo (B textural e B latossólico), considerando as seguintes características: argila natural, argila dispersa e umidade equivalente, e estabeleceram uma relação média de erosão (erodibilidade) para os horizontes superficiais e subsuperficiais para os dois grupamentos de solo do estado (quadro 3). 
Quadro 3: Erodibilidade de solos do Estado de Sầo Paulo em t.h/M]

\begin{tabular}{|l|c|c|}
\hline \multicolumn{1}{|c|}{ SOLO } & $\begin{array}{c}\text { HORIZONTE } \\
\text { SUPERFICIAL }\end{array}$ & $\begin{array}{c}\text { HORIZONTE } \\
\text { SUBSUPERFICIAL }\end{array}$ \\
\hline COM B TEXTURAL & & \\
\hline Podzolizados com cascalho & 0,055 & 0,027 \\
\hline Podzolizados de Lins Marilia (v. Mar.) & 0,049 & 0,023 \\
\hline Podzólico Vermelho Amarelo (v. Laras) & 0,043 & 0,046 \\
\hline Podzolizados de Lins Marilia (v. Lins) & 0,035 & 0,023 \\
\hline Podzólico Vermelho Amarelo Orto & 0,034 & 0,018 \\
\hline Podzólico Vermelho Amarelo (v. Piracic) & 0,028 & 0,019 \\
\hline Mediterrâneo Vermelho Amarelo & 0,023 & 0,021 \\
\hline Terra Roxa Estruturada & 0,018 & 0,011 \\
\hline COM B LATOSSÓLICO & & \\
\hline Latossolo Vermelho Amarelo Orto & 0,022 & 0,009 \\
\hline Latossolo Vermelho Escuro fase arenosa & 0,017 & 0,012 \\
\hline Latossolo Vermelho Amarelo raso & 0,017 & 0,022 \\
\hline Latossolo Vermelho Escuro Orto & 0,015 & 0,022 \\
\hline Solos de Campos do Jordão & 0,015 & 0,013 \\
\hline Latossolo Vermelho Amarelo fase arenosa & 0,013 & 0,007 \\
\hline Latossolo Vermelho Amarelo fase terrạo & 0,012 & 0,003 \\
\hline Latossolo Roxo & 0,012 & 0,004 \\
\hline Latossolo Vermelho Amarelo Húmico & 0,011 & 0,004 \\
\hline
\end{tabular}

Fonte: BERTONI \& LOMBARDI NETO (1990)

Os dados apresentados para os dois agrupamentos de solos mostram que, de maneira geral, os solos podzolizados são mais suscetíveis à erosão. No entanto, BERTONI \& LOMBARDI NETO (1990) ressaltam que, embora alguns solos sejam mais erodíveis que outros, a quantidade de solo perdida pela erosão é influenciada não somente pelo próprio solo, mas também pelo tratamento ou manejo que recebe.

Para a obtenção dos dados de solo da bacia hidrográfica do "Córrego Espírito Santo", além do mapa do Levantamento de Reconhecimentos de Solos do Estado de São Paulo, foi elaborado um esboço morfopedológico da área (figura 5) na escala 1:10.000, pois a área da bacia não permitia a obtenção de dados mais detalhados por não ser compatível com a escala original do Mapa de Solos do Estado de São Paulo.

A partir da identificação dos tipos de solo, os valores de $\mathrm{K}$ foram atribuídos baseados nos dados obtidos por BERTONI \& LOMBARDI NETO (1990), apresentados no quadro 4. 
Figura 5: Esboço morfopedológico da bacia hidrográfica do “Córrego Espírito Santo"

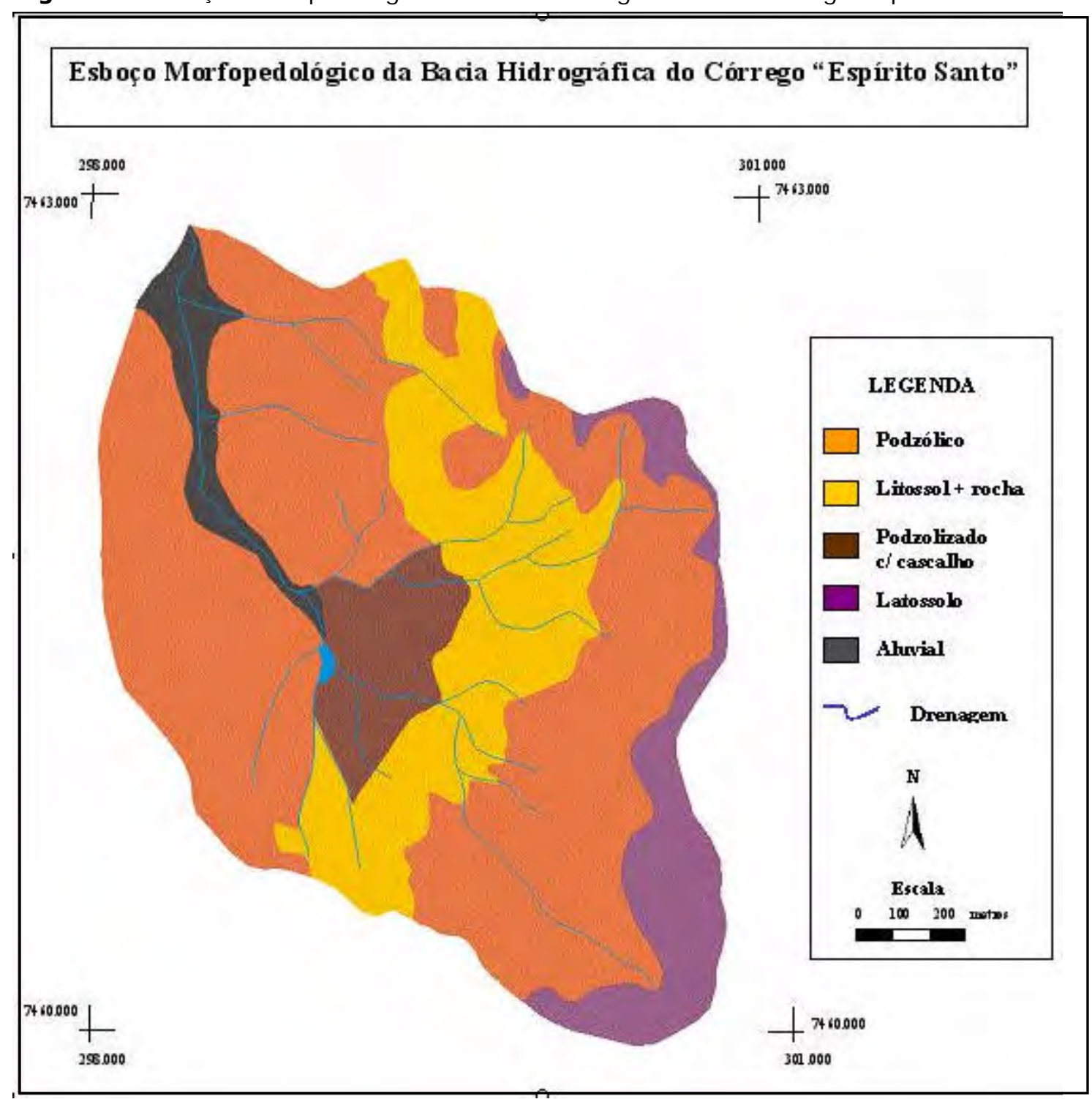

Fonte: Pesquisa de gabinete

É importante ressaltar que, por meio da elaboração do esboço morfopedológico, foi identificado a presença de manchas de Litossol com afloramentos de rochas. Como esta unidade não é contemplada nos agrupamentos estudados por BERTONI \& LOMBARDI NETO, o valor atribuído a ela foi baseado na aproximação das suas características às de outras unidades pedológicas abordadas no estudo. O quadro 4 apresenta os valores utilizados para cada tipo de solo. 
Quadro 4: Tipos de solos encontrados na bacia hidrográfica do córrego "Espírito Santo" e seus respectivos valores de $\mathrm{K}$.

\begin{tabular}{|ll|}
\hline Tipos de solo & Valores de K \\
\hline Podzolizado com Cascalhos & 0,055 \\
Litossol + Rocha & 0,055 \\
Podzólico Vermelho Amarelo orto & 0,034 \\
Latossolo Vermelho Amarelo orto & 0,022 \\
Aluvial & 0,0 \\
\hline
\end{tabular}

\section{Fonte: Trabalho de qabinete}

Uma vez estabelecidos os valores para os tipos de solo, a erodibilidade foi calculada para cada uma das parcelas. Quando em uma parcela havia mais de um tipo de solo, a erodibilidade correspondia à média resultante de seus respectivos valores.

\section{Uso e Manejo (Fator C) e Práticas Conservacionistas (Fator $\mathbf{P}$ )}

O fator C corresponde ao efeito combinado dos diversos tipos de manejos possíveis de serem adotados e da proteção oferecida pela cobertura vegetal.

BERTONI \& LOMBARDI NETO (1990) ressaltam que as perdas de solo ocorridas em um terreno que é mantido continuamente descoberto podem ser estimadas pelo produto dos têrmos R, K, L e S. Porém, se a área estiver cultivada, estas perdas serão amenizadas devido à proteção que a cultura oferece ao solo. Essa redução também é condicionada pelas combinações de cobertura vegetal, seqüência de cultura e práticas de manejo, além do estádio de crescimento e desenvolvimento da cultura. Dessa forma, os efeitos do uso e o manejo não podem ser avaliados individualmente.

STEIN et al. (1987, apud TAVARES \& VITTE, 1993), determinaram valores para o fator
C agrupando as diversas ocupações do solo pelo porte e pela porcentagem de cobertura do terreno, aliado ao conhecimento prévio sobre as etapas de preparo do solo, plantio, colheita e manejo dos restos culturais na área de estudo.

TAVARES (1986, apud TAVARES \& VITTE, 1993) estabeleceu o fator $C$ a partir da comparação de pesquisas que relatavam perdas de solo em diferentes culturas e manejos, possibilitando, com isso, a hierarquização dos diversos usos em relação às proteções que eles ofereciam aos solos. A partir do conhecimento do valor de $C$ para alguns deles, através de pesquisas já realizadas, os demais puderam ser estimados.

Com relação à cobertura vegetal, a proteção oferecida por ela durante o seu ciclo vegetativo é gradual. Em função disso, para efeito de praticidade, BERTONI \& LOMBARDI NETO (1990) dividiram essa proteção em cinco estágios:

- período D (preparo do solo): do preparo do solo até o plantio;

- período 1 (plantio): do plantio até o primeiro mês após o plantio;

- período 2 (estabelecimento): do primeiro até o segundo mês após o plantio; 
- período 3 (crescimento e maturação): do final do segundo mês após o plantio até a colheita;

- período 4 (resíduos): da colheita até o novo preparo do solo.

Desta forma, as intensidades de perdas de solo são computadas para cada um desses estágios e para cada cultura, sob várias condições.

Segundo BERTONI \& LOMBARDI NETO (1990), para a obtenção do valor C, as intensidades de perdas de solo de cada período são relacionadas com dados relativos à chuva, isto é, em relação à porcentagem de distribuição do índice de erosão (EI) anual para determinado local.

$O$ fator $\mathrm{P}$ é a relação entre a intensidade das perdas esperadas com o uso de determinada prática conservacionista e as perdas que ocorrem quando a cultura foi plantada no sentido do declive.

De acordo com BERTONI \& LOMBARDI NETO (1990), as práticas conservacionistas mais comuns para culturas anuais são: plantio em contorno, plantio em faixas de contorno, terraceamento e alternância de capinas.

BERTONI \& LOMBARDI NETO (1990) lembram ainda que em áreas terraceadas costuma-se levar em conta não só o valor P para plantio em contorno como também a redução do comprimento de rampa (L), que vai alterar o fator LS.

CUNHA (1997) ressalta que os efeitos dos dois fatores ( $\mathrm{C}$ e $\mathrm{P}$ ) podem ser avaliados conjuntamente devido à estreita relação entre ambos. A avaliação conjunta de C P é contemplada segundo a proposta de STEIN et al. (1987, apud CUNHA, 1997), apresentada no quadro 5.

Quadro 5: Uso da terra e valores para C $P$

\begin{tabular}{|ll|}
\hline Uso da Terra & Valores de CP \\
\hline Mata & 0,00004 \\
Silvicultura & 0,0001 \\
Citrus & 0,02 \\
Café & 0,02 \\
Cana-de-açúcar & 0,5 \\
Pastagem & 0,01 \\
Cultura anual & 0,02 \\
\hline
\end{tabular}

Fonte: CUNHA (1997)

Para a atribuição do valor de C P na área da bacia do córrego "Espírito Santo" foram consideradas algumas peculiaridades das culturas predominantes na área, em especial a aplicação de cobertura morta sobre o solo. Este tipo de prática é adotado anualmente após o período de poda, sendo que a área onde a cultura está instalada recebe em cada aplicação uma cobertura, em média, de $10 \mathrm{~cm}$ de espessura, permitindo que o solo fique totalmente coberto.

Em função desta prática adotada, o valor atribuído a C P não pode ser o mesmo que é atribuído para outras culturas como o café ou os cítrus. Embora 
todas sejam culturas permanentes, as condições de exposição do solo são distintas. Dada a relevância do grau de proteção oferecido ao solo é possível atribuir a C P um valor similar ao de mata, ou seja, 0,00004 .

\section{Aplicação da Equação Universal de Perdas de Solo (USLE)}

Os dados obtidos para cada fator foram inseridos em uma planilha de cálculo do software Excel 7.0, onde aplicou-se a equação para cada uma das parcelas. O quadro 6 apresenta um fragmento desta planilha.

A partir dos dados obtidos para a estimativa de perda de terra, foram determinadas as seguintes classes: $\leq 0.5$ ton/ha/ano; $0.5-1.0$ ton/ha/ano; 1.0 - 1.5 ton/ha/ano; 1.5 - 2.0 ton/ha/ano e $\geq 2.0$ ton/ha/ano.

A análise dos resultados mostra que, de maneira geral, as estimativas de perda de solo na bacia do córrego "Espírito Santo" são baixas. Considerando-se a área total da bacia, 84\% apresenta estimativa de perda de solo menor ou igual 0.5 ton/ha/ano. Mesmo considerando as áreas com declividade mais acentuada, onde a susceptibilidade à erosão é maior, as perdas de solo não apresentaram valores elevados. A figura 6 ilustra as perdas de terra estimadas para a bacia.

Quadro 6: Fragmento da planilha de cálculo elaborada para estimativa de perdas de terra por erosão na bacia hidrográfica do córrego "Espírito Santo"

Quadro 6: Fragmento da planilha de cálculo elaborada para estimativa de perdas de terra por erosão na bacia hidrográfica do córrego "Espírito Santo"

\begin{tabular}{|c|c|c|c|c|c|}
\hline Parcela & $\mathbf{R}$ & $\mathbf{K}$ & LS & CP & EPS: \\
\hline 16 & 6055 & 0.017 & 26.2 & 0.00004 & 0.11 \\
\hline 17 & 6055 & 0.017 & 7.8 & 0.00004 & 0,03 \\
\hline 18 & 6055 & 0.017 & 1.2 & 0.00004 & 0.00 \\
\hline 19 & 6055 & 0.017 & 2.4 & 0.00004 & 0.01 \\
\hline 20 & 6055 & 0.017 & 17.6 & 0.00004 & 0.07 \\
\hline 21 & 6055 & 0.017 & 2.6 & 0.00004 & 0.01 \\
\hline 22 & 6055 & 0.0 & 1.8 & 0.00004 & 0.00 \\
\hline 23 & 6055 & 0.017 & 16.5 & 0.00004 & 0.07 \\
\hline 24 & 6055 & 0.017 & 31.5 & 0.00004 & 0.13 \\
\hline 25 & 6055 & 0.017 & 32.4 & 0.00004 & 0.13 \\
\hline 26 & 6055 & 0.017 & 26.1 & 0.00004 & 0.11 \\
\hline 27 & 6055 & 0.017 & 19.7 & 0.00004 & 0.08 \\
\hline 28 & 6055 & 0.017 & 3.3 & 0.00004 & 0.01 \\
\hline 29 & 6055 & 0.034 & 6.4 & 0.00004 & 0.05 \\
\hline 30 & 6055 & 0.035 & 11.6 & 0.00004 & 0.10 \\
\hline 31 & 6055 & 0.036 & 4.8 & 0.00004 & 0.04 \\
\hline 32 & 6055 & 0.037 & 8.2 & 0.00004 & 0.07 \\
\hline 33 & 6055 & 0.038 & 24.1 & 0.00004 & 0.22 \\
\hline 34 & 6055 & 0.039 & 7.2 & 0,00004 & 0.07 \\
\hline 35 & 6055 & 0,040 & 7,2 & 0.00004 & 0.07 \\
\hline 36 & 6055 & 0.041 & 10.0 & 0.00004 & 0.10 \\
\hline 37 & 6055 & 0.042 & 36.7 & 0.00004 & 0.37 \\
\hline 38 & 6055 & 0.045 & 10.3 & 0.00004 & 0.11 \\
\hline 39 & 6055 & 0.055 & 11.8 & 0.00004 & 0.16 \\
\hline 40 & 6055 & 0.055 & 27.0 & 0,00004 & 0,36 \\
\hline
\end{tabular}

Fonte: Trabalho de gabinete

* Estimativa de perdas de solo em ton/ha/ano 
Figura 6 - Estimativa de Perdas de Solos na Bacia Hidrográfica do Ribeirão do Espírito Santo, Município de Valinhos, SP (dados em Ton/Há/ano)

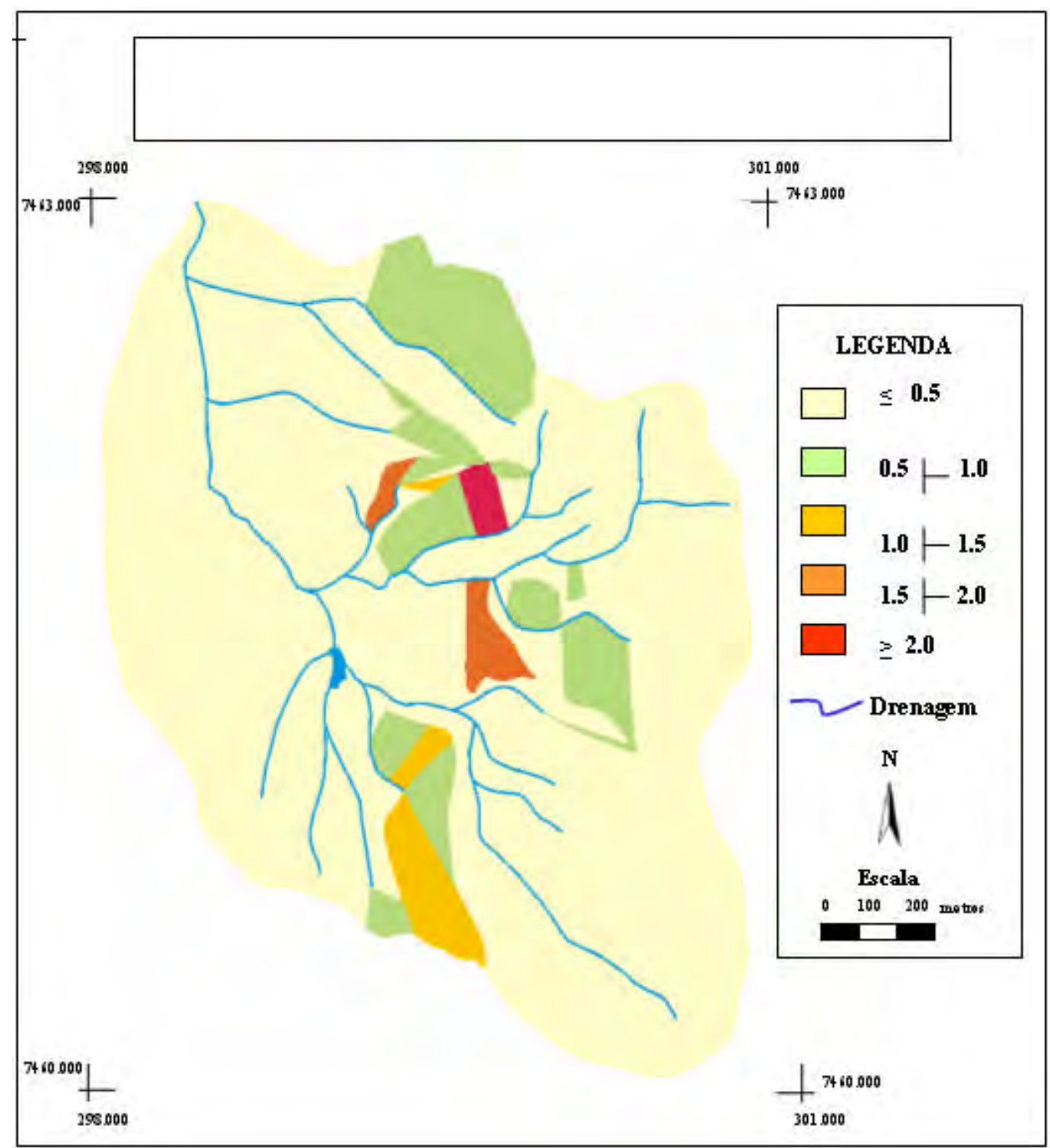

Fonte: Trabalho de gabinete 
Estimativa de perdas de solos em uma bacia hidrográfica sob

\section{Resultados e Discussão}

O trabalho desenvolvido na bacia do córrego "Espírito Santo" apontou que, das 160 parcelas mapeadas, $43 \%$ apresentam rampas com até 100 metros de comprimento e em 31\% o comprimento varia entre 100 e 200 metros, enquanto que a declividade predominante oscila entre 20 e $40 \%$.

De acordo com BERTONI \& LOMBARDI NETO (1990), esses dois componentes do relevo exercem acentuada influência sobre a erosão, pois, o tamanho e a quantidade do material em suspensão arrastado pela água dependem da velocidade com que ela escoa, e essa velocidade é uma resultante do comprimento da lançante e do grau de declive do terreno.

Quanto aos tipos de solo, predominam os que são constituídos de horizonte B textural, que, de acordo com estudos realizados por BERTONI \& LOMBARDI NETO (1990), torna o solo mais suscetível à erosão. Pela ordem aparecem: o Podzólico Vermelho Amarelo, o Litossol com presença de rocha exposta e o Podzolizado com Cascalho.

Com relação ao uso, a área da bacia é ocupada, quase que em sua totalidade, pelo cultivo de frutíferas (figo, goiaba, uva), que, por serem culturas permanentes, exigem menos emprego de atividades no preparo do solo. Mas em contrapartida, são culturas que têm em comum no manejo o uso da poda anual. Isso significa que a densidade foliar destas culturas não é constante durante o ciclo produtivo anual e que, conseqüentemente, ocorrem variações na interceptação foliar, por ocasião das chuvas.

Este aspecto é de extrema importância - embora sejam raros os trabalhos que falam sobre a quantidade interceptada por cada tipo de vegetal - pois é sabido que a cobertura vegetal, em função de sua densidade, pode oferecer maior ou menor proteção ao solo.

Por outro lado, os dados pluviométricos analisados no período de 1974/94 para Valinhos mostram que a precipitação média anual do município é de, aproximadamente, 1500mm. Há predominância de um período chuvoso que se estende de outubro a março, onde ocorre cerca de $72 \%$ da precipitação média anual, sendo que as maiores incidências de chuva concentram-se nos meses de dezembro e janeiro.

A composição destes dados preliminares, embora não fossem suficientes para a obtenção de resultados conclusivos, dava indícios de tratar-se de uma área propícia à erosão dos solos.

Para que as perdas de solo da bacia pudessem ser estimadas, fez-se uso da Equação Universal de Perdas de Solo. De acordo com os dados obtidos, $84 \%$ da área total apresentou uma perda estimada de 0.5 ton/ha/ ano, enquanto apenas $1 \%$ apresentou estimativa de perda de solo acima de 2.0 ton/ ha/ano, sendo que esta área é caracterizada pela presença de declividade acentuada e litossol com rocha exposta.

Assim, os dados obtidos demonstram que as taxas de perda de solo foram muito baixas. Estes resultados podem ser atribuídos às práticas conservacionistas que são adotadas anualmente para as culturas de figo, uva e goiaba, que baseiam-se na incorporação de restos culturais e na formação de uma camada superficial de "cobertura morta". Esta camada impede o contato direto das gotas de chuva com o solo, funcionando como um meio armazenador de água que viabiliza a maior taxa de infiltração em detrimento da taxa de escoamento superficial nas vertentes. Além do que, a mineralização desta matéria orgânica atua no sentido de fornecer maior estabilidade aos agregados do horizonte superficial, e, consequentemente, maior resistência deste horizonte aos processos erosivos.

\section{Considerações Finais}

O desenvolvimento da pesquisa para o cálculo da estimativa de perdas de solo na bacia hidrográfica do córrego "Espírito Santo", em suas várias etapas, permite fazer algumas considerações, a saber: 
a) Embora a Equação Universal de Perdas de Solo seja um importante instrumento para predição, as dificuldades encontradas para a determinação dos fatores que a compõem limitam sua adoção. No entanto, esse agravante tende a diminuir em função das pesquisas desenvolvidas por diversas instituições do país, em especial no Estado de São Paulo.

De qualquer forma, quando é desenvolvido um estudo que classifica e hierarquiza a erosão em uma determinada área, para que os resultados sejam extrapolados para outras áreas é preciso considerar que para sua obtenção foram empregadas técnicas seletivas e avaliação subjetiva, as quais variam conforme a área e a visão do pesquisador.

Por outro lado, na aplicação da equação pelo método cartográfico, os valores atribuídos aos fatores naturais nem sempre são exatos, pois neste processo perdem-se alguns detalhes. Por esse motivo, neste trabalho adotou-se o termo "estimativa" de perdas de solo.

b) Dos fatores que compõem a Equação Universal de Perdas de Solo, o que mais despertou atenção durante o desenvolvimento das pesquisas foi o $C \mathrm{P}$.

Para a determinação do fator C (Uso e Manejo dos Solos), o ideal é que sejam realizados experimentos de campo. Porém, devido ao tempo escasso para o desenvolvimento do trabalho, e considerandose que os fatores $\mathrm{C}$ e $\mathrm{P}$ mantêm estreita relação entre si, optou-se por aplicar o mesmo procedimento usado por CUNHA (1997) e adotar a proposta de STEIN et al (1987), que avalia os dois fatores conjuntamente. Outro aspecto que motivou a adoção deste procedimento foi o fato de não haver, na bibliografia utilizada, estudos que indiquem valores para as práticas conservacionistas utilizadas nas culturas que predominam na bacia.

Pela proposta de STEIN et al (1987), dentre os valores atribuídos aos diversos usos da terra, o menor é para mata nativa. Isso se justifica pelo fato de que, nestas áreas, em alguns casos, a camada de matéria orgânica chega a $50 \mathrm{~cm}$ de espessura. Conseqüentemente, nestes locais, a ação do escoamento superficial é reduzida, prevalecendo os escoamentos sub-superficial e subterrâneo.

Comparativamente, a camada de "cobertura morta" aplicada anualmente sobre o solo onde as culturas estão instaladas cumpre o mesmo papel da matéria orgânica existente na mata nativa. Este fato pôde ser confirmado nos trabalhos de reconhecimento de campo, quando foi possível identificar a inexistência de sinais característicos dos processos erosivos, mesmo com a predominância de solos suscetíveis à erosão e declividade acentuada.

Desta forma, o grau de proteção oferecido ao solo permitiu atribuir a C $P$ um valor semelhante ao estipulado por STEIN para mata nativa.

c) Para a realização de trabalhos dessa natureza, os materiais cartográficos, como mapas temáticos e cartas topográficas, constituem-se em fontes básicas de informações para o desenvolvimento satisfatório das pesquisas. Porém, este tipo de estudo muitas vezes exige escalas que possibilitem maior riqueza de detalhes, que, no entanto, nem sempre são fáceis de se obter.

Nesse sentido, a maior dificuldade encontrada durante o desenvolvimento das pesquisas foi a escassez de material cartográfico na escala 1:10.000, em especial, as cartas pedológicas. Apesar de existirem diversos trabalhos envolvendo o mapeamento dos solos, principalmente no Estado de São Paulo, a grande maioria, é editada na escala $1: 100.000$, onde os solos são mapeados em associações, o que acaba por dificultar a sua utilização em trabalhos onde os detalhes são alcançados somente através de escalas maiores. 
Estimativa de perdas de solos em uma bacia hidrográfica sob

o cultivo de frutíferas, no município de Valinhos (SP), pp. $45-64$

\section{Nota}

${ }^{1}$ Para a aplicação dos valores de L, foram considerados os valores intermediários das classes, os quais são apresentados na 2 a coluna do quadro 5 .

\section{Bibliografia}

BERTONI, José e LOMBARDI NETO, Francisco. Conservação do solo. São Paulo - SP. Ícone, 1990, 355p.

CENTRO NACIONAL DE ENSINO E PESQUISAS AGRONÔMICAS. Comissão de Solos. Levantamento de Reconhecimento de solos do Estado de São Paulo. Rio de Janeiro, Serviço Nacional de Pesquisas Agronômicas, 1960, 634p.

CUNHA, Cenira Maria Lupinacci da., Quantificação e mapeamento das perdas de solo por erosão com base na malha fundiária. Instituto de Geociências e Ciências Exatas, UNESP, Rio Claro, 1997, 93p.

CUNHA, Sandra Baptista da, GUERRA, Antonio José Teixeira. Degradação ambiental. In: GUERRA, Antonio José Teixeira e CUNHA, Sandra Baptista da (org.). Geomorfologia e Meio Ambiente. Rio de Janeiro: Bertrand Brasil, 1996, 394p.

CHRISTOFOLETTI, Antonio. Geomorfologia. São Paulo: Edgard Blücher, 2a edição, 1980, $188 \mathrm{p}$

DAEE. Banco de dados pluviométricos do Estado de São Paulo (atualizado até 1997). DAEE, Secretaria de Recursos Hídricos Saneamento e Obras, Governo do Estado de São Paulo, CD ROM, 1999.

GUERRA, Antonio José Teixeira. Processos erosivos nas encostas. In GUERRA, Antonio José Teixeira e CUNHA, Sandra Baptista da. Geomorfologia: uma atualização de bases e conceitos. 3a ed. Rio de Janeiro: Bertrand Brasil, 1995, p. 149-209.

GUERRA, Antonio José Teixeira. O início do processo erosivo. In: GUERRA, Antonio José
Teixeira, SILVA, Antonio Soares da, BOTELHO, Rosangela Garrido Machado (org.). Erosão e conservação dos solos, conceitos, temas e aplicações. Rio de Janeiro: Bertrand Brasil, 1999, 340p.

IPT Mapa Geológico do Estado de São Paulo, 1981

IPT Mapa Geomorfológico do Estado de São Paulo, 1981

JOIA, Paulo Roberto. Novas trajetórias da alta tecnologia no Brasil, sob a influência da ação do Estado: uma análise do pólo tecnológico de Campinas, SP.Tese de Doutorado, IGCE, UNESP - Rio Claro, 2000, p. 163-170.

LOMBARDI NETO, Francisco, BERTONI, José. Erodibilidade dos solos paulistas. Campinas, SP, Instituto Agronômico, 1975. 12p. Boletim Técnico, 27.

LOMBARDI NETO, Francisco, MOLDENHAUER, W. C. Erosividade da chuva: sua distribuição e relação com perdas de solo em Campinas, SP. In: Encontro Nacional de Pesquisa sobre Conservação do Solo, 3, Recife, 1980. Anais...fl. 13.

LOMBARDI NETO, Francisco, SILVA, I. R. \& CASTRO, O. M. Potencial de erosão das chuvas do Estado de são Paulo. In: Encontro Nacional de Pesquisa sobre Conservação do Solo, 3, Recife, 1980. Anais...fl. 13-A.

MACHADO, Paulo Affonso Leme. Direito Ambiental Brasileiro 7ạ edição, revista, atualizada e ampliada de acordo com as Leis $\mathrm{n}^{\text {os }}$ 9.433/97 e 9.605/98. São Paulo, Malheiros Editores Ltda, 1998, p. 359-361. 
OLIVEIRA, Ana Maria Franklin de. Os dilemas da municipalização da saúde na contexto de uma região metropolitana: o caso de Campinas. Tese de Doutorado, Instituto de Economia, UNICAMP, Campinas, 1995, p. 636.

PIRES, Mário. Valinhos - Tempo e Espaço. Publicações da Academia Campinense de Letras, no 37. Campinas, 1978, 131p.

SEMEGHINI, Ulisses Cidade. São Paulo no Limiar do Século XXI: Cenários da Urbanização Paulista - Regiões Administrativas. Fundação SEADE e Secretaria de Planejamento e Gestão. São Paulo, 1982, 197p.

TRICART, Jean. As relações entre a morfogênese e a pedogênese. Campinas, Notícia Geomorfológica, 1968, p. 5-18.
TRICART, Jean. Ecodinâmica. Rio de Janeiro, IBGE, Diretoria Técnica, SUPREN, 1977, 91p.

VEIGA, José Eli da. Problemas da transição à agricultura sustentável. Est. Econ. São Paulo, v. 24, no especial, 1994, p. 9-29.

VERDI, Adriana Renata. Metropolização de Campinas: possibilidades no entorno da Grande São Paulo. Dissertação de Mestrado, FFLCH - USP, 1997, p. 68-104.

TAVARES, Antonio Carlos, VITTE, Antonio Carlos. Erosão dos solos e assoreamento de represas: o caso de Monte Aprasível (SP). Geografia, 18 (1), 1993, p. 51-95.

VITTE, Antonio Carlos. Metodologia para cálculo de perdas de solo em bacias de drenagem. Bol. Par. de Geociências, no 45, Ed. da UFPR, 1997, p. 59-65.
Trabalho enviado em julho de 2006

Trabalho aceito em agosto de 2006 